\title{
Experimental Studies on Effect of Nailing in Cohesion-Less Soil
}

\author{
${ }^{1}$ Mohd. Rameez Raza Sheikh, ${ }^{* 2}$ Pravin. B. Kulkarni, ${ }^{3}$ E.M Gonnade \\ 1,2,3 Dept. of Civil Engineering, Shri Ramdeobaba College of Engineering and Management, Katol Road, Nagpur- \\ 440013 \\ Email: Sheikhms_1@rknec.edu,kulkarnipb@rknec.edu,gonnadeem@rknec.edu
}

Received: 13th November 2019, Accepted: 31st January 2020, Published: 29th February 2020

\begin{abstract}
The anchorage in the form of soil nailing can be used for stabilizing weak natural soil slopes. It can also be used for steepening of new or naturally existing soil slopes. The nail anchorage in the soil can be in the form of reinforcement and in the different materials with different cross section area. The most of the failure of nail in soil have been reported as pullout failure due to tension on the nail, particularly in sandy soil. Because of increased cost and safety concerned the field test to determine pullout force is difficult. Therefore the laboratory studies were carried out in simulated conditions. In this research work, the laboratory investigation were carried out to observe the effect of tensile (pullout force) force on the soil nail in sandy soil. The pullout force on the nail was gradually increased and the corresponding displacement was recorded till failure of the nail due to continues sliding. The test results were compared to Standard values in earlier studies. It has been shown that a simple loading frame with testing tank model can be used to simulate the pullout load-displacement relationship and to determine peak pullout force of different type of nails. The various parameters studied were embedded length of the nail, the type of surface, the material and cross-section of nail.

\section{Keywords}

Nailing, Cohesion-Less Soil, Pull-Out Force, Pull-Out Resistance, Pull-Out Failure

\section{Introduction}

The dumped loose soil either from deposited excavated material are likely to fail. These slopes can be stabilized by providing anchorage to the soil in the form of nail. The nail anchorage can be at any inclinations or horizontal. The application of nailing can be for stabilizing the embankment for road and railways as well for stabilizing the mine dumps.[6] The major advantages are economical and faster construction and suitability in the area where heavy construction equipment movement is difficult.

The most important feature of soil nailing as opposed to the ground anchor technique is that the nail force is passively generated by the displacement of the soil, and the displacement is in turn due to the nail force. The construction sequence of placing the nails and facing walls, and the stiffness and continuity of facing walls on the excavation surface may also affect the behavior of nailed slopes.[1] There is thus a complex interaction between a nail, facing wall and the surrounding soil, and for this reason, any complete solution for the mechanics of soil nailing, if it exists, should take account of the displacements of both nails and the soil.[2]
\end{abstract}

\section{Failure Modes of Soil Nail}

Generally, there distinct failure modes have been observed for a soil nail system. They are as follows.

1. Facing failure: This type of failure develops in a soil nail wall having long nail with high tensile strength and modest facing strength facing. In facing failure, the head strength will not contribute the stability of active zone.

2. Pull out failure: This occurs when soil nail has limited penetration into the passive region and possesses high tensile capacity and facing strength. The force generated in active region will depend upon length of reinforcement passive zone, and is expressed as.

Where, Q- is mobilized pull out per unit length,

$$
\mathrm{Q}=\pi \mathrm{qD}
$$

q- Is mobilized shear stress acting around the perimeter of soil nail

D- Is the effective diameter of the nail hole

Considering the single nail segment subjected to a tensile force, $\mathrm{T} 0$, at one end, and shown in fig 1 , the tensile force can be estimated from the interference shear stresses as:

$$
\mathrm{dT}=\pi \mathrm{qDDHdx}=\mathrm{Qdx}
$$

If the length of the soil nail embedded in the passive zone is Lp, then the total pullout force is estimated as:

$$
\mathrm{F}=\mathrm{Q}^{*} \mathrm{Lp}
$$


3. Nail tendon failure: Such failure occurs when sufficient length of nail is provided but with modest tensile stress.[4]

\section{Experimental Set-up for Laboratory Pullout Test}

The experimental setup consisted for tests are tank, model nails, reaction frame, wire rope and pulleys. These are describing in detail as follows as shown in Fig 1.

a). Sand tank: The sand tank is of size $0.9 \mathrm{~m}$ in length $\mathrm{x} 0.9 \mathrm{~m}$ in width $\times 0.9 \mathrm{~m}$ in height. There one hole in one wall in front wall for allowing nail installation. The position of nail is at center of wall at a distance 0.55 from bottom and 0.45 from top.

b). Loading frame \& pullout system: The loading frame is consist of three pulley, and the wire rope connection which one end is hook to the nail and on other end there provision to applied load gradually. [3]

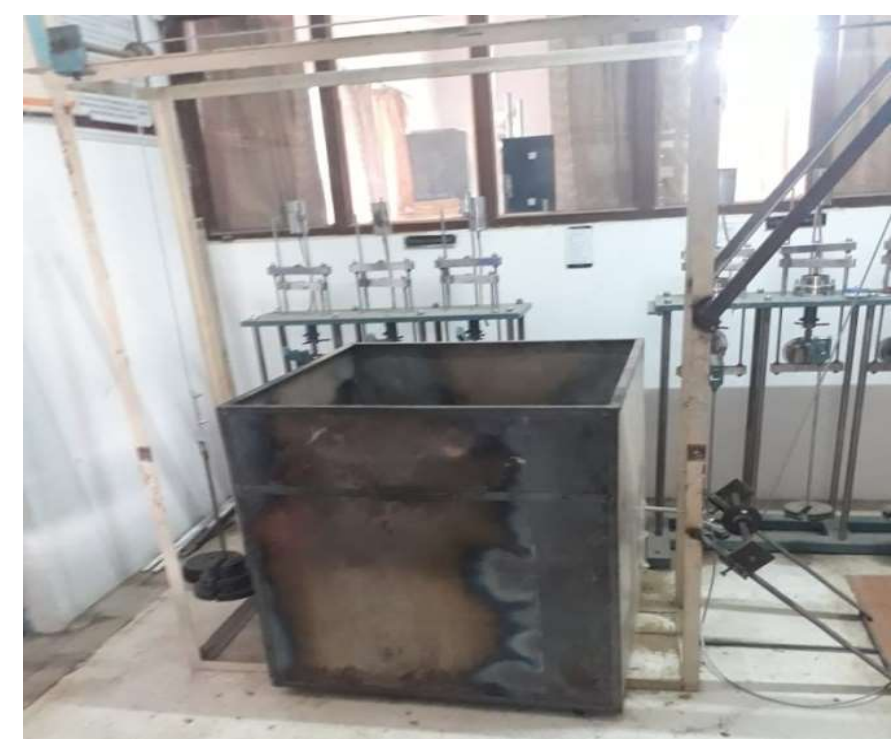

Fig 1: Model Tank

\section{Nail Details}

For increasing the stability of slopes of sandy soil, the nails were inserted in the soil which was placed in the tank. The insertion of nail increases the overall shear resistance of the slopes. The nails of diameter was $6 \mathrm{~mm}$, length was $600 \mathrm{~mm}$ and slope height was $900 \mathrm{~mm}$. The various inclination used was $0^{0}$ (horizontal), $5^{0}$ and $7^{0}$. [8] The nails used were plain, 2-anchors and 3-anchors with cement grout. The load was applied gradually on one end and corresponding displacement was measured by using dial gauge till complete failure.[5]

\section{Testing Procedure}

Initially front face of tank is drilled for installation of nail of $6 \mathrm{~mm}$ diameter, and insertion of nail is done surrounded with cement grout as shown in fig 2 . While inserting nail and casing is also provided for alignment of nail and proper placing of nail. Initially load test was performed on the nail with an arrangement of pulley and wire rope which gradually increases the load on the nail to pull it in outward direction.[7] As the load is given the deflection of nail is noted with the help of marking on nail while inserting. The load is applied gradually by means of load increment on other side of wire rope and deflection can be seen on front face of nail inserted. The procedure carried out till failure. 


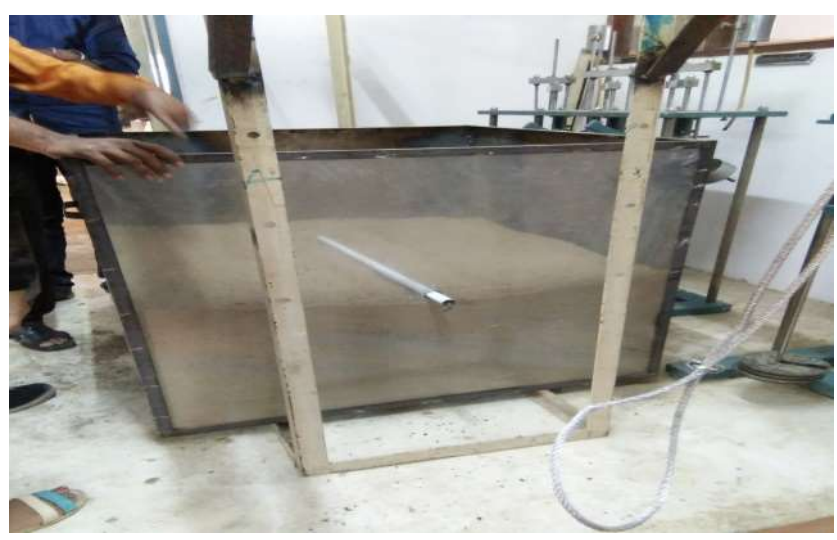

Fig 2: Installation of Nail

\section{Result and Discussion}

The results obtained for various inclinations and anchoring combinations are shown in the following fig. 3 , 4 and 5.

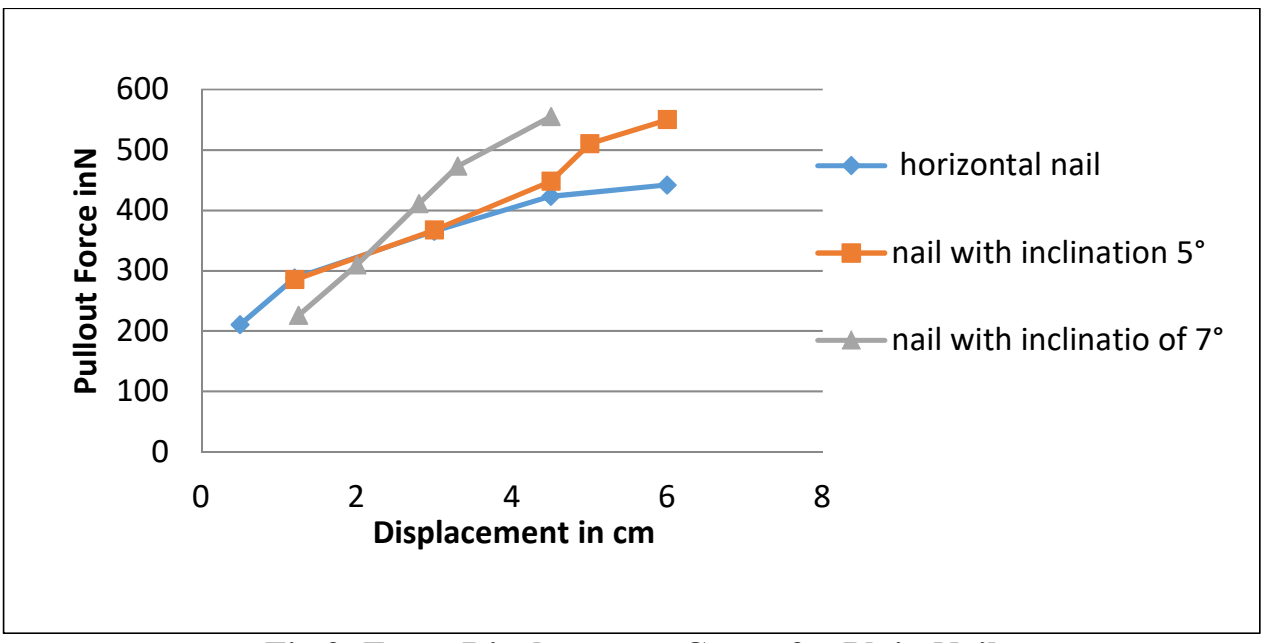

Fig 3: Force Displacement Curve for Plain Nail

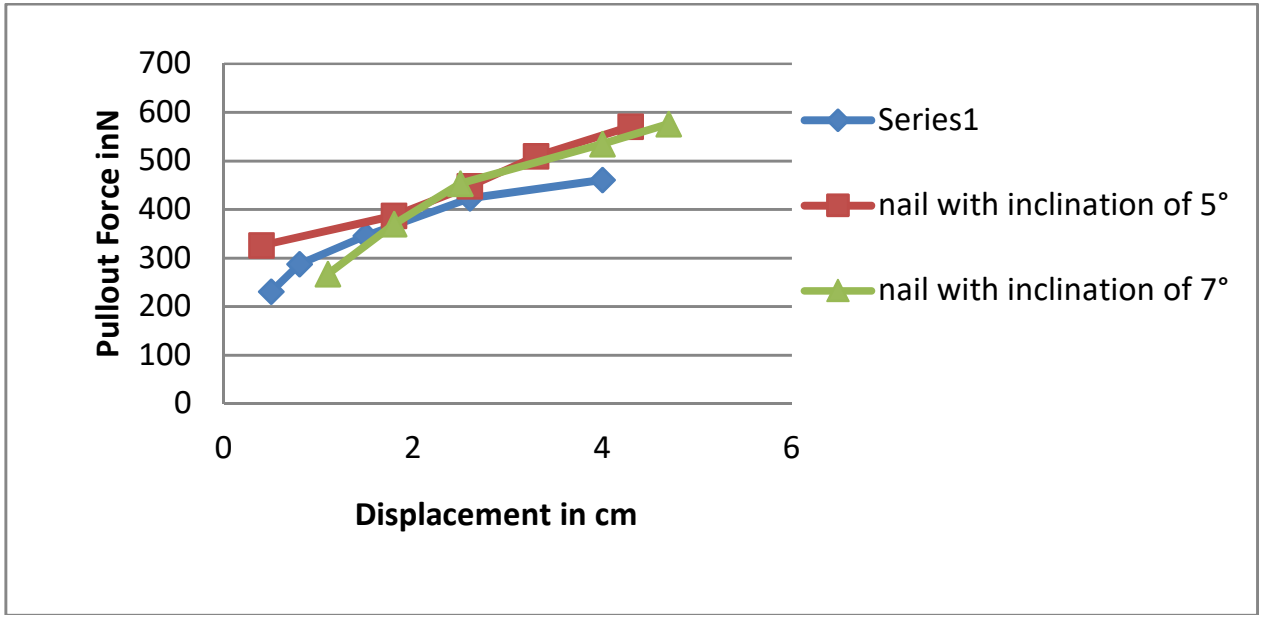

Fig 4: Force Displacement Curve for 2-Anchor Nail 


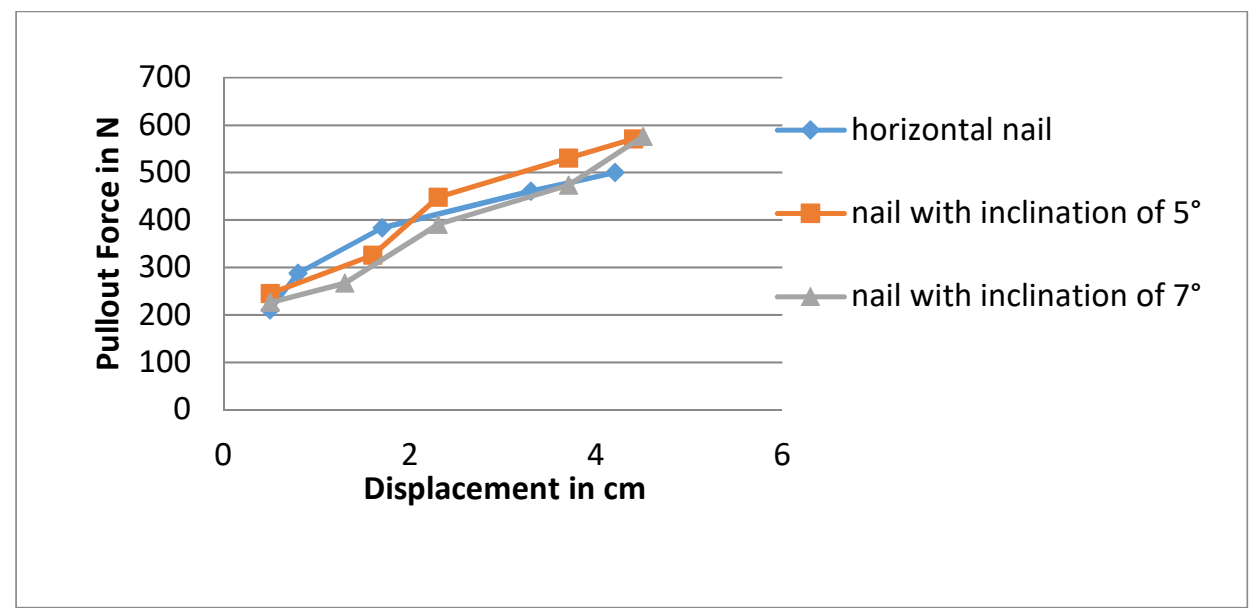

Fig 5: Force Displacement Curve of 3-Anchor Nail

In above fig no. 3 represents that for plain nail, pullout force goes on increasing as the inclination increases In above fig no. 4 shows that for nail with 2 anchors, the maximum pullout is for inclination of 50 afterwards it slightly decreases

In above fig no. 5 , for nail with 3 anchors also the maximum pullout is for inclination of 50 .

\section{Conclusion}

- Nailed slopes shows better performance as compare to natural slopes in terms of stability. Higher the number, inclination and larger the length of nail, better is the performance of nail can be seen.

- The optimum pullout force is seen in anchor nail with face inclination of $10^{\circ}$. The study has demonstrated that the laboratory test can provide the fairly good estimation of the field pullout resistance.

- For cement grouted nail without inclination to the face the skin friction was applied but due to no bounding with surrounding resistance applied was not much to hold the nail for greater load applied.

- The optimum pullout force for anchor nail was greater than the nail with cement grout, the nail and soil mechanism is essentially dominated by friction (bond) between them which leads to the higher pullout force to be taken for failure of nail.

- The provision of nail without inclination is not suitable, Anchor nail with inclination of $10^{\circ}$ or more is most suitable.

- The comparative increase in pullout force for anchor nail was $30 \%-40 \%$.

\section{References}

1) B.Pradhan, L.G.Tham, Z.Q.Yue, S.M.Junaidean and C.F.Lee, 'Soil-nail pullout in loose fill material'

2) Bridle, R. J, 'Soil nailing-analysis and design.' Ground Eng., 22(6), 52-56, (1989).

3) Clough, G. W., and Duncan, J. M. 'Finite-element analyses of retaining wall behavior.' J. Soil Mech. Found. Div., 97(12), 1657-1673.(1971).

4) Dr. Amit Prashant and Ms. Mousmi Mukherjee 'Soil nailing for slopes stability', Indian Institute of Technology, Kanpur

5) Feijo, R. L., and Erhlich, M. 'Nail pullout tests in residual soils in Rio De Janeiro-Brazil.', Soil-Rock America 2003,

6) Kouji tei, 'study of soil nailing in sand'

7) S.A.Tan, P.H.Ooi, T.S.Park, and W.L.Cheang, 'Rapid pullout test on dry sand'-

8) Samirsinh P Parmar, Dharmsinh Desai University, Nadiad; 'study for comparison of ultimate load in cohesionless soil by soil nailing-horizontal v/s inclined nailed' 